\title{
Design of a wave energy converter system for the Colombian Pacific Ocean
}

\author{
Diseño de un sistema de conversión de energía del oleaje para el Océano Pacífico Colombiano
}

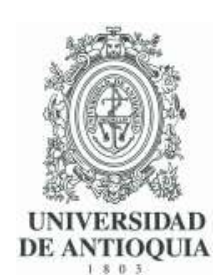

Fredys Romero Menco iD ${ }^{1}$, Ainhoa Rubio-Clemente (iD 1, 2 , Edwin Chica iD ${ }^{1 *}$
${ }^{1}$ Departamento de Ingeniería Mecánica, Universidad de Antioquia. Calle 70 \# 52-21, C. P. 050010. Medellín, Colombia.
${ }^{2}$ Facultad de Ingeniería, Tecnológico de Antioquia-Institución Universitaria. Calle 78b, \# 72A-220, C. P. 050090. Medellin, Colombia.

\section{CITE THIS ARTICLE AS:}

F. Romero, A. Rubio and E. Chica. "Design of a wave energy converter system for the Colombian Pacific Ocean", Revista Facultad de Ingeniería Universidad de Antioquia, no. 94, pp. 8-23, Jan-Mar 2020. [Online]. Available: https://www . doi.org/10.17533/ udea.redin. 20190406

\section{ARTICLE INFO:}

Received: April 02, 2019 Accepted: April 29, 2019 Available online: April 29, 2019

\section{KEYWORDS:}

Buoy; ocean wave energy; wave mechanics

Boya; energía de las olas oceánicas; mecánica de las ondas
ABSTRACT: This paper details the mechanical design of a wave power generation system comprising a buoy that houses a set of mechanical devices and a linear generator. The system proposed transforms the heaving movement of the buoy in a rotational movement of the arm that houses the linear generator. Firstly, the conceptual design and the operation of the system is exposed. Secondly, the conditions of the waves in the zone of interest are presented; in this case, the device was designed to work in the Colombian Pacific Ocean. Afterwards, the dynamic model of the buoy and the linear generator are deduced starting off the movement laws. To solve the resulting equation, Ansys Aqwa ${ }^{\circledR}$ numerical software is used to know the behavior of the device under the features of the swell conditions. Finally, the simulation results under real conditions are presented and compared to the response under incident regular wave. To determine the amount of electric power generated, a calculus routine in Matlab ${ }^{\circledR}$ is implemented. Throughout the numerical code, the electric power generated is calculated at each time step, and the average electric power is solved subsequently. It was found that under regular and irregular swell conditions the amount of electricity produced was 1.17 and $0.5 \mathrm{~kW}$, respectively. In this regard, the device proposed here is an interesting option for populations inhabiting near coastlines far from existing electricity grids.

RESUMEN: Este artículo detalla el diseño mecánico de un sistema de generación de energía a partir de las olas, el cual está compuesto por una boya, un conjunto de dispositivos mecánicos y un generador lineal. El sistema propuesto transforma el movimiento de levantamiento de la boya en un movimiento de rotación del brazo que alberga el generador lineal. En primer lugar, se expone el diseño conceptual y el funcionamiento del sistema. Posteriormente, se presentan las condiciones de las olas en la zona de interés; en este caso, el dispositivo fue diseñado para funcionar en el Océano Pacífico colombiano. A continuación, el modelo dinámico de la boya y el generador lineal se deducen a partir de las leyes de movimiento. Para resolver la ecuación resultante, se utiliza el software numérico Ansys Aqwa ${ }^{\circledR}$ para conocer el comportamiento del dispositivo bajo las características de las condiciones del oleaje. Finalmente, los resultados de la simulación en condiciones reales se presentan y comparan con la respuesta en la ola regular incidente. Para determinar la cantidad de energía eléctrica generada, se implementa una rutina de cálculo en Matlab®. Con el código numérico, se calcula la energía eléctrica generada en cada paso de tiempo, y posteriormente se determina la energía eléctrica promedio. Se encontró que bajo condiciones de oleaje regulares e irregulares la cantidad de electricidad producida fue de 1,17 y $0,5 \mathrm{~kW}$, respectivamente. En este sentido, el dispositivo propuesto constituye una opción interesante para las poblaciones que viven cerca de las líneas de costa alejadas de las redes eléctricas existentes.

\section{Introduction}

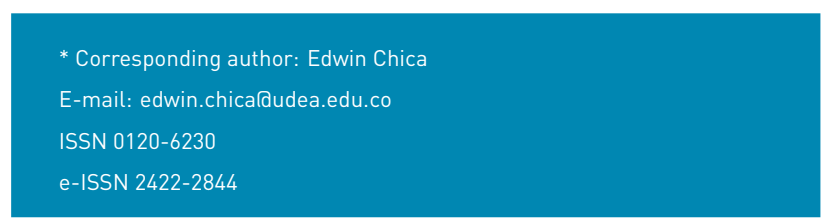

Ocean waves provide an abundant, clean and renewable source of energy. Wave energy can be considered a form of solar energy due to the unequal heating of the Earth's 
surface by sun leads to the occurrence of high and low pressures areas. These pressure gradients cause wind; as winds blows over large bodies of water, part of its energy is imparted to the water, resulting in waves; i.e., when wind blows across the sea surface, it transfers the energy to the waves [1-4]. The size and frequency of the waves depend on the length of time, wind speed and distance, known as the fetch, wind blows over the water surface. Long fetches tend to generate the most energetic wave climates. Consequently, coastlines exposed to prevailing wind directions and long fetches tend to have the most energetic wave climates [3-6].

Ocean wave energy has several advantages over other forms of renewable energy as waves are more constant, more predictable and with higher energy densities, enabling devices to extract more power from smaller volumes at lower costs and reduced visual impact [3-7]. In general, wave energy is harnessed by the movements of the device, either floating on the surface of the ocean or operating below the sea level. The energy is captured by oscillating motions at frequency of waves.

Many different techniques to convert wave energy into electric power have been studied in the recent years and, consequently, various types of technologies aiming at harvesting ocean waves have been proposed. Therefore, a number of possibilities are available to date, but no one seems to be predominant and none clearly superior engineering solutions is established yet. In the literature, different classifications can be found; some of them relative to the distance from the shoreline, the generation type or the power conversion are available nowadays $[1-3,8]$.

For every sea or ocean region around the world, the energy level and properties of the waves are unique. Therefore, it is necessary to design a wave energy converter (WEC) depending on its expected location in order to maximize the energy output at the location. One method for optimizing the design of a given WEC is to optimize its geometric shape, or geometric configuration, so as it will perform to its maximum efficiency in a specified manner. Therefore, in the design, maximizing the power production of the wave energy converters for the majority of the time is required $[1-4,9]$.

Colombia has a high energy potential due to its geographical and climate diversity across its territory. The energy resource availability of the country could facilitate the incorporation of renewable energy generation market, diversifying the energy matrix [10-12]. In Colombia, according to the Mining and Energy Planning Unit (UPME, by its acronym in Spanish) the dominant source of energy is the hydropower due to its generous hydrology regime and favorable orography provide the basis for a large hydropower potential. It is important to note that a large hydro-based power system may be susceptible to climate variability that could affect the hydrology regime and, therefore, the reservoir capacity of hydropower plants [13-17]. In this regard, new source of renewable energy or non-conventional renewable energies are prudent to be examined in Colombia. In addition, these alternative sources of energy can play an important role in the energy supply for the non-interconnected zones [12-14]. Colombia, today, has many regions with geographical difficulties for extending electricity transmission line, especially those communities located on the Colombian Pacific Coast. Therefore, the absence of reliable power and energy supply is an established challenge to the quality of life of people inhabiting these regions. This is due to most activities are dependent on affordable and sufficient energy for productive processes [18, 19].

Nowadays, technologies involving wind turbines, photovoltaic systems, WEC, hydrokinetic turbines and small scale hydropower systems merit more attention from rural electrification programs in developing countries to generate electricity for lighting, refrigeration, irrigation pumping, water supplies, crop processing, agro-industries and small commercial and manufacturing establishments, which use electricity for productive purposes [20-23].

The Colombian Pacific region has immense ecological, hydrographic, mining and forest richness. However, it has low-density population, scarce infrastructure, and some areas do not have electric power supply networks due to the fact that their own geographic, economic and demographic characteristics, among others, the expansion of the networks to the national interconnected system do not have environmental and financial viability. According UPME, energy generation in the non-interconnected zones of the Colombian Pacific Coast relies mainly on diesel technologies, followed by small hydroelectric plant, hybrid and photovoltaic systems, wind power and biomass [17-19, 24].

Due to the large extent of geographic area, the dispersion and small size of communities in the non-interconnected zones, no detailed statistics on energy consumption in households and energy requirements of these areas are still provided. Therefore, initiatives to improve the quality of services provided in these regions, increasing energy coverage and promoting a penetration increase of renewable energy sources would have to depend on the electricity generation in mini-grids or individual solutions.

Under this scenario, in this work, a WEC, which converts the displacement motion of the buoy into electric energy, has been developed for communities located on the 
Pacific Coast of Colombia. The work is focused on the development of a dynamic model for predicting the WEC power capture as a function of the wave energy spectrum and geometry of the buoy and the linear generator. With the aim of gaining insight into the performance of the WEC, numerical modelling was applied in this work using the software Ansys Aqwa ${ }^{\circledR}$. The numerical model simulated the behavior of the WEC in the time domain by considering the wave excitation forces, the radiation forces produced by the WEC itself, the hydrostatic restoring forces and, very importantly, the forces in the power take-off (PTO) system.

\section{Methods and materials}

\subsection{Wave energy}

The commonly method used for describing the energy in real sea waves is the wave energy spectrum $(S(f))$. This is a distribution of the wave energy of a given location as a function of the wave frequency $(f)$. Two main parameters were used to describe the wave power $(P)$ : the significant wave height $\left(H_{m}\right)$ and the average wave period (T). $H_{m}$ is calculated as described in Equation 1. The term $\mathrm{H}_{m}$ is often used to describe the height of a spectrum and is defined as the average height of the highest one-third wave in a wave spectrum. This means that $H_{m}$ is the mean value of the highest $33 \%$ of the waves [25] and can be calculated using the Equation 1.

$$
H_{m}=4 \sqrt{m_{0}}
$$

where $m_{0}$ is the integral of the wave energy spectrum, which is provided by Equation 2 [25].

$$
m_{0}=\int_{0}^{\infty} S(f) d f
$$

The total stored energy (E) in a wave per unit area of the sea surface is the sum of the kinetic and potential energy. The potential energy of the wave is due to the elevation of water from the waves trough up to the crest. E can be expressed in terms of $\mathrm{H}_{\mathrm{m}}$ and $S(f)$ according to Equation 3 [25].

$$
E=\rho g \int_{0}^{\infty} S(f) d f=\frac{\rho g H_{m}^{2}}{16}
$$

where $\rho$ refers to the density of the fluid and $g$ is the acceleration due to gravity.

The wave power level (P) per unit width in a wave is given by Equation 4. $P$ is generally proportional to $\mathrm{H}_{\mathrm{m}}$ squared [26].

$$
P=\rho g \int_{0}^{\infty} v_{g}(f) S(f) d f=\frac{\rho g^{2} H_{m}^{2} T}{64 \pi}
$$

where $v_{g}(f)$ is the group velocity, which is expressed as Equation 5 [25].

$$
v_{g}(f)=\frac{g}{4 \pi f}=\frac{g T}{4 \pi}
$$

WEC captures the energy contained in ocean waves and uses it to generate electricity, as mentioned above. There are three main categories; oscillating water columns that use trapped air pockets in a water column to drive a turbine; oscillating body converters that are floating or submerged devices using the wave motion lup/down, forwards/backwards, side to sidel to generate electricity; and overtopping converters that use reservoirs to create a head and subsequently drive turbines. On top of that, each category can be subdivided according to the technologies used to convert wave energy into pneumatic/mechanical energy (rotation/ translation), their power systems (air turbines, hydraulic turbines, hydraulic engines), their structures (fixed, floating, submerged), and their positioning within the ocean (shoreline, near shore, off shore] [26-28].

In this work, a WEC with oscillating body converter was designed due to one of the advantages of floating devices over fixed devices is that they can be deployed in deeper water, where the wave energy is greater. In this regard, designing the geometric configuration of the converter depending on its expected location is required in order to maximize the energy output at that location.

\subsection{Device operation}

In Figure 1, the conceptual design of the device can be seen. When an incoming wave reaches the buoy, it is displaced throughout the z-axis direction a distance equal to the wave amplitude. The arm is pivoted at $D$ point; so that the vertical movement caused by the incoming wave produces a rotational movement of the arm. This rotation generates an angle $(\theta(t))$ measured between the calm water level and the arm position; this angle is a function of time and the incoming wave amplitude; it is directly the responsible to generate the electric power.

The design of the converter shown in Figure 1 allows its location at the shore and can be placed above the sea (in shallow water), integrated in a breakwater, in a dam or fixed to a cliff. The main advantage of this converter is its ease of maintenance and installation since in most cases the location is accessible. Moreover, they do need neither mooring systems nor a long length of sea cable to connect the WEC to the electric grid. However, at the shoreline, waves contain less energy because of their interaction with the seabed. On the other hand, the lack of suitable land sites also can cause difficulties for deploying this system [25-28]. 
The linear generator proposed here is composed of three parts: a stator, a translator and guides. The generator is inside the arm body, so that the inclination angle of the arm is the same as the generator. The translator moves along the guides, so when the inclination angle reaches the specified value $(\phi)$, the movement of the translator becomes imminent, according to the theory of dry friction [29]. The translator has the permanent magnets with the magnetic domains disposed in alternated form (N-S-N). The movement of the translator along the guides causes a temporally change of the magnetics domains; according to Faraday's induction law, this variation causes an induced current at the stator's coils. The minimum angle that causes the movement of the translator $(\phi)$ depends on the static frictional coefficient value, which will be shown in the next section. As the wave passes through the buoy, the process described above is repeated but, in this case, in the opposite direction.

\subsection{Material}

The environmental conditions play a fundamental role in the selection of the materials that will constitute the parts of the design proposed. Due to the exposition to sea water, the arm parts; especially the part housing the generator, were made of AISI 316 steel, owing to anticorrosive properties that this material exhibits under marine conditions. On the other hand, due to the generator is isolated from the external atmosphere, for manufacturing the guides and the external housing, AISI 1020 steel was used. Regarding the stator's coils, magnetic wire reference 14 AWG was used taken into account that the power generated is aimed at household consumption. The buoy used in the system corresponded to the floating dock commercial modules Candock ${ }^{\circledR}$, which can provide unlimited configurations for the floating surface; i.e., the floating cubes can be assembled to create the desired shape and size. The blocks were held together tightly and firmly with special connecting pins. All parts were lightweight and easy to handle. They were made of high density polyethylene resin. It is noteworthy that Candock ${ }^{\circledR}$ cubes are remarkably resistant to impact, climate change and the adverse effects of water.

\subsection{Dynamics modeling of the WEC}

A buoy can be continuously floating in the ocean and undergo a large amount of dynamic motion, which could be feasibly harnessed for power generation. A schematic view of the buoy in the ocean is given in Figure 1. Due to the wave action, the buoy has a position $Z$ from its equilibrium position. Taking the vertical direction like z-axis and analyzing the movement at this direction; Newton's second law for the buoy motion can be represented as
Equation $6[2-4,30]$

$$
m_{B} \ddot{Z}(t)=F_{E x c}+F_{A r c h}-F_{G}-F_{A-B}+F_{P T O}
$$

where $m_{B}$ is the mass of the buoy including all the internal components; $F_{G}$ is the gravity force equal to $m_{B} g ; g$ is the gravity; $Z$ is the vertical displacementes of the buoy and $\ddot{Z}(t)$, the buoy acceleration at z-axis. Additionally, the variable $F_{E x c}$ in Equation 6 is the excitation wave force. This force corresponds to the effect of the wave acting on a body in the water. $F_{E x c}$ can be separated into three components: (a) the Froude-Krylov force $\left(F_{F K}\right)$, (b) the diffraction force $\left(F_{\text {Diff }}\right)$, and $(c)$ the radiation force $\left(F_{\text {Rad }}\right)$. $F_{F K}$, produced by the wave momentum, is imparted onto the submerged body. In turn, $F_{\text {Diff }}$ and $F_{\text {Rad }}$ come from the disturbances to the surrounding fluid $[1-3,31]$. Because of the contribution of the diffraction component has significantly smaller order of magnitude compared to the other two components, the effect of this force component can be considered as negligible for this analysis. This approximation generally is known as the Froude-Krylov approximation, which is quite useful taking into account that the calculus of diffraction component is quite complicated [3-6, 32]. Thus, $F_{E x c}$ is determined by Equation 7.

$$
F_{E x c}=F_{F K}+F_{R a d}+F_{D i f f}
$$

As mentioned above, the diffraction component is equal to zero in this analysis; then, the new expression for $F_{E x c}$ is expressed by Equation 8 .

$$
F_{E x c}=F_{F K}+F_{R a d}
$$

The Froude-Krylov component corresponds to the force that the floating body experiences when it is fixed in a mean position and the incoming wave impacts with it [25, 32]. The mathematical expression for this component is summarized in Equation 9.

$$
F_{F K}=\int_{-\infty}^{\infty} h_{E x c}(t-\tau) \eta_{w}(\tau) d \tau
$$

where $h_{E x c}$ is the excitation force impulse function, which is of non-causal nature $[10,29]$. The non-causality implies that the movement of the buoy is not due to the wave that is just passing underneath it, it may be an effect of the wave that is $30 \mathrm{~m}$ away the buoy and still has not reached the buoy or a vessel to thousands of kilometers [32]. $\tau$ is the wave period. $\eta_{w}$ is the water free surface elevation that is a function of the period $(\tau)$. Furthermore, $h_{E x c}$ is a function of $t-\tau$; this indicates that the system is time-invariant linear system. This fact means that the system has the same characteristics now as in the past and in the future [25]. The solution in time domain of Equation 4 is represented by Equation 10.

$$
F_{F K}=h_{E x c}(t) \otimes \eta_{w}(t)
$$




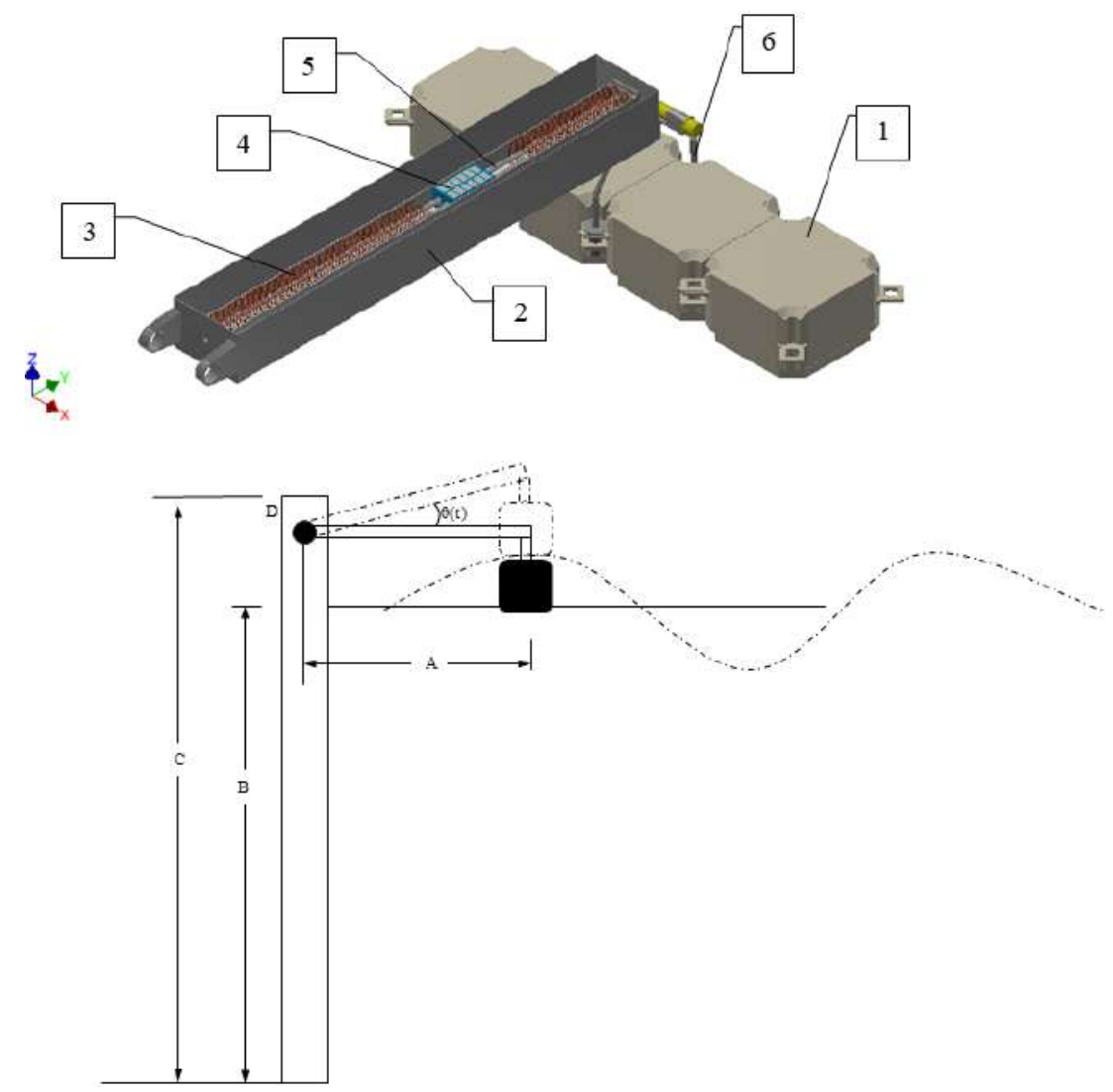

Figure 1 Wave energy converter system. At the top, a detailed design of the device proposed in this work can be seen: 1) Floating buoy; 2) External case; 3) Stator's coils; 4) Translator; 5) Translator Guides; 6) Arm - Buoy Joining. The parts from 2 to 6 constitute the arm. In the bottom, a sketch of a functioning WEC system is illustrated

where the symbol $\otimes$ indicates the convolution between $h_{E x c}$ and $\eta_{w}$

In general terms, $F_{\text {Rad }}$ is the force that the body experiences, owning that itself movement causes radiated waves in the water, which in turn exert a force in the buoy body [32]. This component is divided into two components. The first component is related to the effect caused when the buoy oscillates ostensibly, leading to a large water added mass; this component interrelates the added mass $\left(m_{\infty}\right)$ with the body acceleration in this case, the z-axis acceleration $(\ddot{Z}(t))$. The second component is related to the power that the body losses when generating the water waves; this component interrelates the body velocity $(\dot{Z}(t))$ with the hydrodynamic damping coefficient $\left(K_{H y d}\right)[33,34]$. The added mass $\left(m_{\infty}\right)$ physically represents an additional weight of the buoy due to the water surrounding it. Meanwhile, the hydrodynamic damping $\left(K_{H y d}\right)$ physically represents a damping effect, which is a product of the water viscosity acting over the body oscillation stopping it. Equation 11 corresponds to the equation that represents $F_{R a d}$.

$$
F_{\text {Rad }}=-\int_{-\infty}^{t} K_{H y d}(t-\tau) \dot{Z}(\tau) d \tau-m_{\infty} \ddot{Z}(t)
$$

Equation 12 expresses the temporal solution of the integral in Equation 11.

$$
-\int_{-\infty}^{t} K_{H y d}(t-\tau) \dot{Z}(\tau) d \tau=-K_{H y d}(t) \otimes \dot{Z}(t)
$$

Substituting Equation 12 into Equation 11, the radiation component expression is obtained (Equation 13).

$$
F_{R a d}=-K_{H y d}(t) \otimes \dot{Z}(t)-m_{\infty} \ddot{Z}(t)
$$

Therefore, substituting Equation 10 and Equation 13 into Equation $8, F_{E x c}$ is determined by Equation 14.

$$
F_{E x c}=h_{E x c}(t) \otimes \eta_{w}(t)-K_{H y d}(t) \otimes \dot{Z}(t)-m_{\infty} \ddot{Z}(t)
$$

Moreover, $F_{A r c h}$ is the buoyance force acting on the buoy. The Archimedes' principle says that the buoyancy force that act in a submerged body is equal to the weight of the displaced fluid volume; and it can be located at the centroid of the displaced volume. According to this principle, the 
buoyancy force can be calculated as indicated in Equation 15.

$$
F_{\text {Arch }}=\rho g V_{\text {submerged }}
$$

where $\mathrm{g}$ is the gravitational acceleration.

Analyzing the buoy of the device designed, using Figure 2, it is evident that the floating body has a prismatic shape; thus the volume of the fluid displaced has a variation in time. This can be expressed as Equation 16.

$$
V_{\text {submerged }}=X Y Z(t)
$$

In Equation 16, $X, Y$ and $Z$ ( $t$ ) are the submerged width, depth and the height, as illustrated in Figure 2. Now, substituting Equation 16 into Equation 15, the buoyancy force as a function time is represented by Equation 17.

$$
F_{\text {Arch }}=\rho g X Y Z(t)
$$

In Figure 2, the forces on the buoy can be observed; $F_{E x c}$ changes in magnitude and direction with time as PTO force. Nevertheless, in the sketch, the direction of these forces have been defined, but it is only representative.

In turn, the term $F_{P T O}$ is the force associated with the PTO system, which corresponds to the force that the power take-off exerts on the oscillating buoy. When a lineal control is estimated to the take-off system of a wave energy converter, $F_{P T O}$ is modeled as a mass-spring-damper system. The equation governing the behavior of the system is a second order lineal equation $[5,32]$. The PTO force can be calculated as expressed in Equation 18.

$$
F_{P T O}=-m_{P T O} \ddot{Z}(t)-R_{P T O} \dot{Z}(t)-S_{P T O} Z(t)
$$

where $R_{P T O}$ and $S_{P T O}$ are the damping mechanical coefficient and the stiffness coefficient, respectively, associated with the PTO system $[5,25]$. As observed in Figure 1, for the device proposed here, the transformation system of wave energy into electricity does not have connection with the buoy; therefore, this term is negligible in the dynamic analysis of the system presented in this work.

Finally, $F_{B-A}$ in Equation 1 is the arm buoy force. This force is due to the effect that exerts the arm weight ( $\left.W_{\text {arm }}\right)$ on the buoy. In order to know the value of this parameter, a static analysis is conducted from Figure 3. The values of the distances $F$ and $H$, as well as the arm weight, are compiled in Table 1. From the static equilibrium, applying the torque summation to $D$ point, Equation 19 is obtained.

$$
\curvearrowleft \sum M_{z}=0=F_{B-A} F-W_{a r m} H
$$

From Equation 19, the value of $F_{B-A}$ is found using Equation 20.

$$
F_{B-A}=\frac{W_{a r m} H}{F}
$$

According to Newton's third law, the force that the arm exerts on the buoy has the same value and inverse direction to the force that the buoy exerts on the arm; therefore, the expression determining the effect that the arm exerts on the buoy is represented by Equation 20.

Now, when Equation 14, 17 and 20 are replaced in Equation 6, the equation of the buoy motion can be rewritten as Equation 21.

$$
\begin{gathered}
m_{\text {sys }} \ddot{Z}(t)=h_{E x c}(t) \otimes \eta_{w}(t)-K_{H y d}(t) \otimes \dot{Z}(t) \\
-m_{\infty} \ddot{Z}(t)+\rho g X Y Z(t)-\frac{W_{\text {arm }} H}{F}-m_{\text {buoy }} g
\end{gathered}
$$

When the effect due to gravitational force on the float and the buoyancy force are unified, a new force $\left(F_{\text {res }}\right)$ is generated, which can be calculated using Equation 22 $[5,34,35]$.

$$
F_{\text {res }}=\left\{m_{\text {buoy }} g+\rho g X Y\right\} Z(t)=K_{\text {res }} Z(t)
$$

where $K_{r e s}$ is called "hydrostatic restoring coefficient", whose value can be calculated by Equation 23 .

$$
K_{\text {res }} \approx \rho A_{\text {Proy }} g
$$

$A_{\text {Proy }}$ corresponds to the perpendicular area projected by the buoy at the $X Y$ plane. Now, by substituting Equation 22 into Equation 21 and analogous terms are grouped, the equation of the buoy motion is, finally, Equation 24.

$$
\begin{gathered}
\left(m_{s y s}+m_{\infty}\right) \ddot{Z}(t)=-K_{H y d}(t) \otimes \dot{Z}(t)+ \\
K_{r e s} Z(t)-h_{E x c}(t) \otimes \eta_{w}(t)-\frac{W_{a r m} H}{F}
\end{gathered}
$$

Equation 24 corresponds to the equation that describes the temporal behavior of the device presented in this work. In order to know this behavior, Equation 24 should be solved by using numerical methods. Several software packages can be used to find the behavior of floating buoys under the effect of an incident wave; some of them are open source codes, others are packages under license. In this work, to carry out the numerical modelling of WEC, Ansys Aqwa ${ }^{\circledR}$ package was used to find the response of the buoy under swell specific conditions of sea in the Colombian Pacific Ocean. The software Ansys Aqwa ${ }^{\circledR}$ has different modules to carry out frequency and time domain analyses of marine structures. The elements of the WEC were treated as diffracting elements, so the support was configured to be fixed in a place. Once the WEC geometry was meshed, the frequency-dependent hydrodynamic coefficients were obtained using the hydrodynamic diffraction module and they were stored in a hydrodynamic database. Then, the coefficients were used to solve the dynamic equation of the WEC (Equation 24) in the hydrodynamic time response module. 


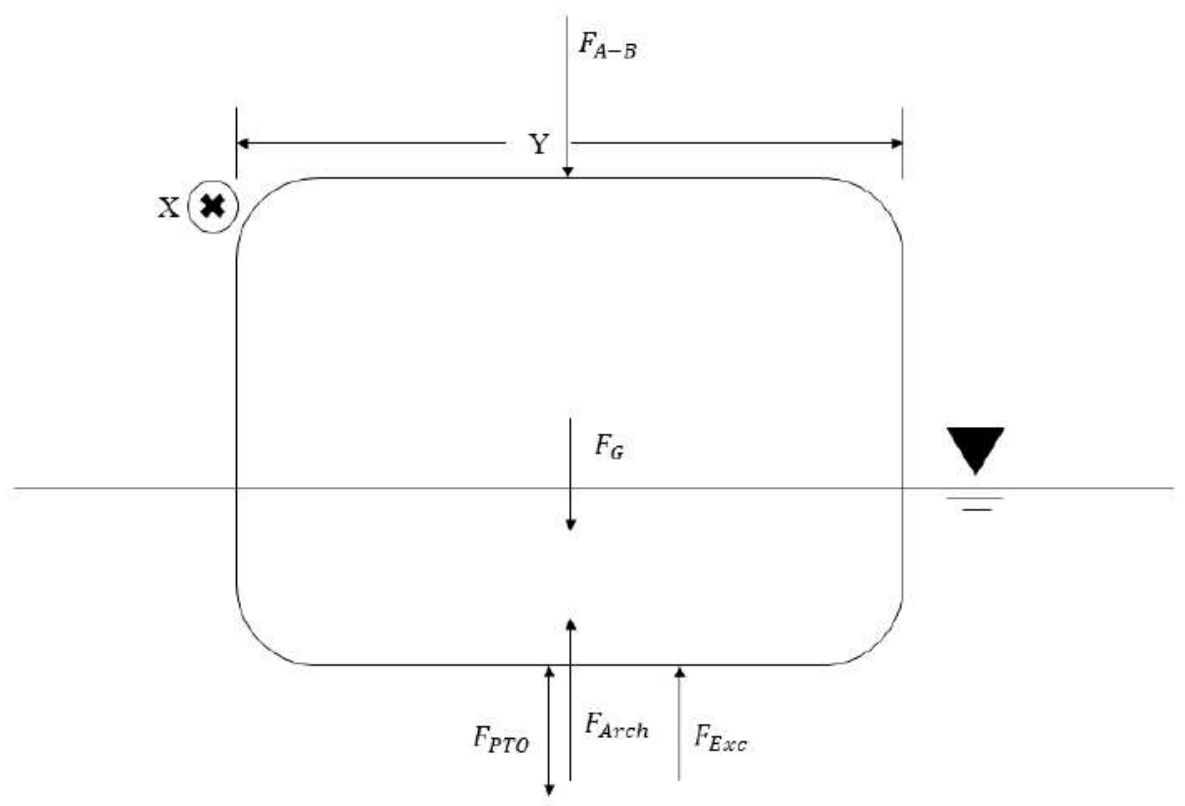

Figure 2 Floating body image to determinate the displaced fluid

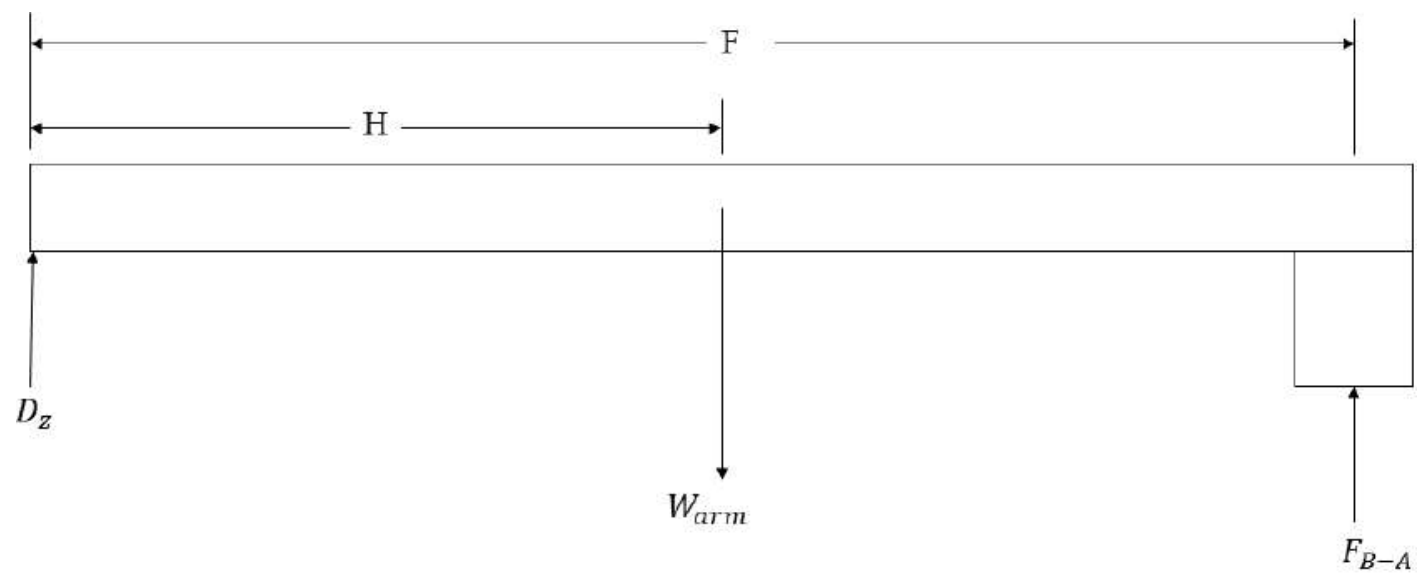

Figure 3 Free-body diagram to determine the force exerted by the arm on the buoy

\subsection{Dynamic analysis of the linear generator}

To harvest the wave energy and convert it into electric energy, transforming the wave movement in a relative movement between the coils and the permanent magnets is required. For this purpose, several systems have been developed. Generally, these systems have a mechanism that transforms the buoy displacement into rotational movement. In this regard, recently, the development of systems that take advantage of the buoy movement without requiring an intermediate mechanism has taken force in the electric power generation from waves. These devices are known as linear generators. As the conventional rotatory generators, these machines work under the Faraday's Induction law. When the translator moves, a magnetic domain change with time is observed, which produces an induced current in a loop of conductive material, according to the mentioned law. In the dynamic model shown in Equation 24, the mass of the translator was considered as negligible for this analysis in comparison with the mass of the rigid arm.

The linear generator proposed here works using the principle of inclined plane. To deduce the equations, Figure 4 is employed. In the figure, the working principle of linear generator is illustrated. When the inclination angle $(\theta)(t)$ reaches a determined value $(\phi)$, the movement is imminent. $\theta(\mathrm{t})$ was obtained from submerged height $Z$ (t), which can be found from Equation 24. In accordance with the dry friction laws, this angle is known as "angle of repose". This angle is only a function of the static friction coefficient and it can be defined as Equation 25.

$$
\phi=\tan ^{-1} \mu_{s}
$$



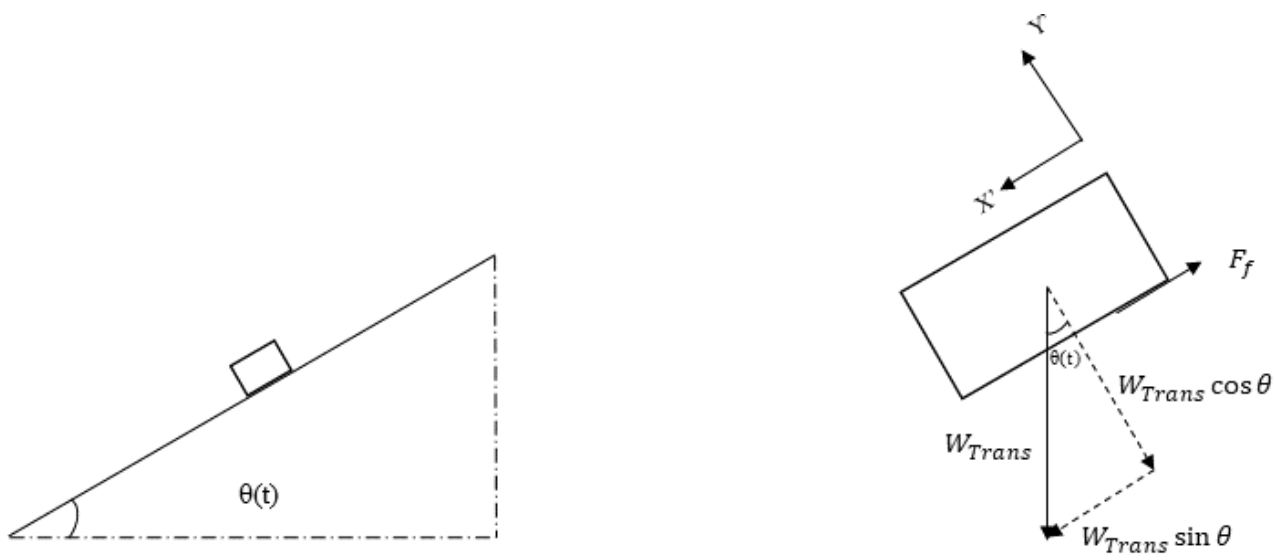

Figure 4 Illustrative outline work linear generator. Free-body diagram of the translator

where $\mu_{s}$ is the static friction coefficient. This corresponds to the resistance that should be overcome to begin the movement of a body respect to other one [29]. This coefficient is caused by the irregularities between the surfaces in contact, and it is independent on the magnitude of the contact surface area. Therefore, the unique variable of interest is the static friction coefficient. In order to facilitate the movement of the translator along the guides, the translator has two pairs of linear bearings in contact with the guides, minimizing the static friction coefficient (Table 1) and, subsequently, the value of $\phi$, so that harvesting any wave elevation.

Table 1 Values of arm length, arm mass and friction coefficients of translator

\begin{tabular}{ll}
\hline Variable & Value \\
\hline $\mathrm{A}$ & $2.2 \mathrm{~m}$ \\
$\mathrm{~B}$ & $10.6 \mathrm{~m}$ \\
$\mathrm{C}$ & $11.2 \mathrm{~m}$ \\
$\mathrm{~F}$ & $2.1 \mathrm{~m}$ \\
$\mathrm{H}$ & $1.4 \mathrm{~m}$ \\
Linear bearing $\left(\mu_{s}\right)$ & 0.025 \\
Linear bearing $\left(\mu_{k}\right)$ & 0.001 \\
Arm mass & $91.99 \mathrm{~kg}$ \\
\hline
\end{tabular}

Nevertheless, when the movement begins, the translator movement is governs by the Newton's second law. According to Figure 4 and the reference system given, the expression for the movement is represented by Equation 26.

$$
\swarrow^{+} \sum F_{x^{\prime}}=m_{\text {Trans }} a_{x \prime}
$$

where $m_{\text {Trans }}$ is the mass of the translator and $a_{x^{\prime}}$ is the acceleration of the translator throughout $x^{\prime}$-direction.

The force responsible for the movement of the translator is the component of the weight throughout $x^{\prime}$-direction, as presented in Figure 4. Hence, Equation 26 can be written as Equation 27.

$$
m_{\text {Trans }} a_{x^{\prime}}(t)=W_{\text {Trans }} \sin \theta(t)-\mu_{k} W_{\text {Trans }} \cos \theta(t)
$$

In Equation 27, $\mu_{k}$ is the dynamic friction coefficient whose value is given in Table 1. As $W_{\text {Trans }}$ is equal to $m_{\text {Trans }} g$, simplifying this expression, $a_{x}$, is represented by Equation 28.

$$
a_{x^{\prime}}(t)=g\left\{\sin \theta(t)-\mu_{k} \cos \theta(t)\right\}
$$

Considering the kinematics of rectilinear motion, the equations for velocity and the position for the movement of the translator are represented by Equation 29 and 30, respectively.

$$
\begin{aligned}
v(t) & =\int a_{x^{\prime}}(t) d t \\
x^{\prime} & =\int v(t) d t
\end{aligned}
$$

Finally, for calculating the electric power produced, according to Montoya-Andrade (2014), the instant electric power generated is determined from Equation 31 [32].

$$
P_{\text {ins }}(t)=\frac{2 \pi \varphi}{L} \dot{x}^{\prime}(t) \cos \left(\frac{2 \pi \varphi x^{\prime}(t)}{L}\right) * i_{\text {line }}
$$

where $\varphi$ is the magnetic flux, which is equal to $N \varphi_{i}$, being $\varphi_{i}$ the magnetic flux per magnets and $\mathrm{N}$ the number of coils of the stator. $L$ is the distance between poles of the same polarity. These values are given in Table 2. The power depends on the current $\left(i_{\text {line }}\right)$ and the amount of resistance present in the system. A winding of an electric generator can be represented as a $R L$ equivalent circuit. If a RL circuit is considered as a system with input and output, the input is the voltage drop $\left(V_{\epsilon}(t)\right)$ across the circuit and the output is the current $\left(i_{\text {line }}(t)\right)$ through the circuit. Both parameters are variable in time $V_{\epsilon}(t)$ across the circuit can be expressed as Equation 32.

$$
V_{\epsilon}(t)=\frac{2 \pi \varphi}{L} \dot{x}^{\prime}(t) \cos \left(\frac{2 \pi \varphi x^{\prime}(t)}{L}\right)
$$


By Ohm's law, $i_{\text {line }}$ can be expressed as Equation 33.

$$
i_{\text {line }}(t)=\frac{V_{\epsilon}(t)}{R_{T}}
$$

where $R_{T}$ is total resistance. It can be expressed as Equation 34.

$$
R_{T}=R_{g}+j L_{g}
$$

where $R_{g}$ is the resistance of the stator, $j$ is the imaginary unit, and $L_{g}$ is the inductance of coil. The calculation of inductance of coils is based in the empirical formulations; therefore, the values obtained are approximate [34]. The inductance can be determinated by Equation 35 .

$$
L_{g}=\frac{\mu N^{2} A}{l}
$$

In Equation 35, $\mu$ represents the magnetic permeability of the coil core, here it is assumed to be made of AISI 1020 steel; $\mathrm{N}$ is the coil number; $l$ is the length of the coil and A refers to the cross-section area to the magnetic flux. These values are given in Table 2 .

On the other hand, the resistance of the stator can be also determined by using the Ohm's law. The resistance can be calculated as Equation 36 [36].

$$
R_{g}=\rho_{m} \frac{l}{S}
$$

In Equation 36, $\rho_{m}$ is the resistivity of the material, $l$ refers to the cable length and $S$ is the cross-section area of the cable. In Table 2, the values of these variables for the device proposed are presented.

\section{Results and discussion}

As mentioned above, to know the temporally behavior of the wave energy converter proposed here, Ansys Aqwa ${ }^{\circledR}$ package was used. Aqwa is a BEM code based on the principles of linear wave theory, so the frequency-domain response has the assumptions of incompressible, irrotational and inviscid flow. The WEC system shown in Figure 1 was modeled in Ansys Aqwa ${ }^{\circledR}$. In the software, first, a hydrodynamic diffraction simulation was executed in order to know the values of the $m_{\infty}$, hydrodynamic damping coefficient and $F_{F K}$, and its variation in the frequency. Secondly, a hydrodynamic time response simulation was executed to know the behavior in time of the buoy. Finally, with the elevation time results, a Matlab ${ }^{\circledR}$ routine was implemented to determine the power electric generated. However, it is highly important to know the sea conditions in the Colombian Pacific Ocean first of all. For this purpose, studies on the spectral wave condition in the Colombia Pacific Ocean were consulted. For example, Portilla et al., in 2015, carried out a research with the purpose of characterizing the specific conditions
Table 2 Properties and values used to determine the electric power generated

\begin{tabular}{ll}
\hline Variable & Value \\
\hline $\begin{array}{l}\text { Magnetic flux } \\
\text { per magnet phase }\left(\boldsymbol{\varphi}_{i}\right)\end{array}$ & $4.745^{*} 10^{-3} \mathrm{~W}$ \\
\hline Stator coils $(\boldsymbol{N})$ & 2000 \\
\hline $\begin{array}{l}\text { Distance between } \\
\text { poles }(\boldsymbol{L})\end{array}$ & $56 \mathrm{~mm}$ \\
\hline Magnetic permeability $(\boldsymbol{\mu})$ & $200 \frac{T m}{A}$ \\
\hline Stator length $(\boldsymbol{l})$ & $1.6 \mathrm{~m}$ \\
\hline $\begin{array}{l}\text { Cross-section area } \\
\text { of the magnetic } \\
\text { flux }(\boldsymbol{A})\end{array}$ & $0.02011 \mathrm{~m}^{2}$ \\
\hline $\begin{array}{l}\text { Electric resistivity } \\
\text { of the material } \\
\left(\boldsymbol{\rho}_{m}\right)\end{array}$ & $0.0171 \frac{\Omega m^{2}}{\mathrm{~m}}$ \\
\hline $\begin{array}{l}\text { Stator length } \\
\text { of the cable } \\
\text { (I) }\end{array}$ & $740 \mathrm{~m}$ \\
\hline $\begin{array}{l}\text { Cross-section } \\
\text { area of the cable } \\
(\boldsymbol{S})\end{array}$ & $\mathrm{NdFeB}$ \\
\hline $\begin{array}{l}\text { Magnetic field per } \\
\text { magnet phase }\end{array}$ & $\mathrm{N} 35$ \\
\hline $\begin{array}{l}\text { Magnets used in } \\
\text { the translator }\end{array}$ & $0.73 \mathrm{~T}$ \\
\hline \begin{tabular}{l} 
Magnet grade \\
\hline
\end{tabular} & $\mathrm{mm}{ }^{2}$ \\
\hline
\end{tabular}

of the swell near to the Colombian Pacific coast [37]. To do this, authors analyzed the time records of 4 buoys owned by DIMAR (Dirección General Marítima de Colombia) located along the Pacific coast. The buoys are part of a local monitoring network that has been working since 2009. The system has several gaps due to failure or maintenance troubles. These buoys are moored near to continental shelf at Tumaco (Nariño); Gorgona Island (Cauca); Buenaventura (Valle del Cauca) and Bahía Solano (Chocó). The length of the record is $30 \mathrm{~min}$ with intervals of $1 \mathrm{~h}$ between records.

From the measures of the spectrum conducted by other researchers [37], it was found that the swell is constituted mostly by 129 frequencies from 0.0 to $0.64 \mathrm{~Hz}$; distributed at regular intervals of $0.005 \mathrm{~Hz}$. Subsequently, the data were statistically treated to obtain the statistical-geometric description parameters. The locations and values are given in Table 3.

Regarding to the wave direction, from the analysis of the swell accomplished by other researchers [37], the dominant swell direction on Colombian Pacific Ocean was found to be $60^{\circ}$ from the Equator. On the other hand, it is important to know which places have potential to generate electricity from the exploitation of the energy from 
Table 3 Statistical-geometric parameters of 4 buoys [37]

\begin{tabular}{llllll}
\hline Location & $\begin{array}{l}\text { Measurement } \\
\text { period }\end{array}$ & $\begin{array}{l}\text { Significant } \\
\text { wave height } \\
\left(\boldsymbol{H}_{m, 0}\right)\end{array}$ & $\begin{array}{l}\text { Zero } \\
\text { crossing } \\
\text { period } \\
\left(\boldsymbol{T}_{m-1,0}\right)\end{array}$ & $\begin{array}{l}\mathbf{E}\left(\mathbf{w} / \mathbf{m}^{2} \mathbf{J}\right. \\
\text { Equation } \\
\text { (3) }\end{array}$ & $\begin{array}{l}\mathbf{P}(\mathbf{w} / \mathbf{m}) \\
\text { Equation } \\
\text { (4) }\end{array}$ \\
\hline Tumaco & Dec/2009-Dec/2012 & $1.01 \mathrm{~m}$ & $6.86 \mathrm{~s}$ & 642.34 & 3439.90 \\
Gorgona Island & May/2011-Oct/2012 & $1.13 \mathrm{~m}$ & $7.76 \mathrm{~s}$ & 804.04 & 4870.77 \\
Buenaventura & May/2011-Feb/2013 & $0.96 \mathrm{~m}$ & $8.21 \mathrm{~s}$ & 580.31 & 3719.33 \\
Bahía Solano & Jun/2011-Jul/2011 & $1.17 \mathrm{~m}$ & $10.61 \mathrm{~s}$ & 861.97 & 7139.47 \\
\hline
\end{tabular}

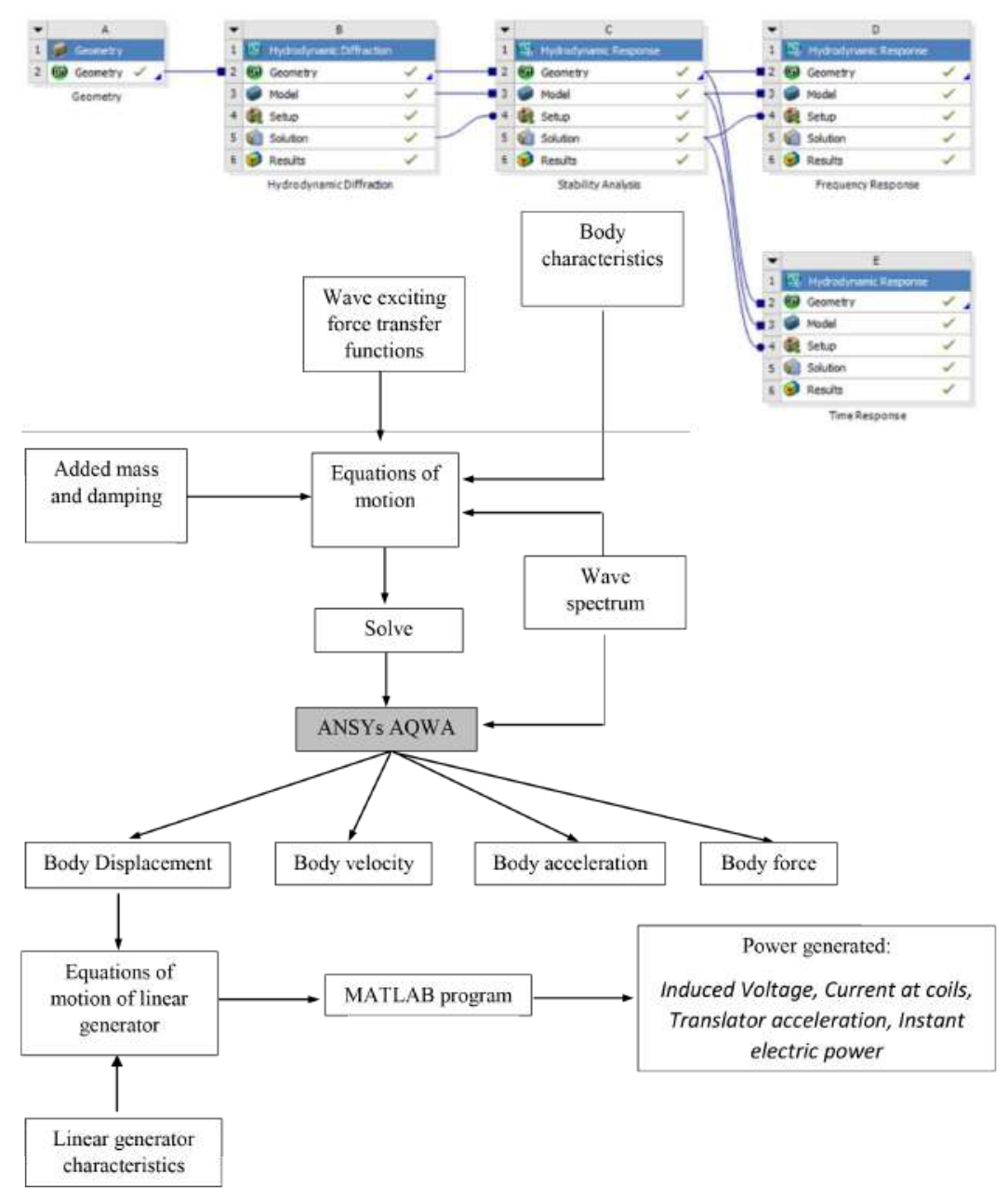

Figure 5 Program flow chart

waves. Osorio and co-workers conducted an exhaustive evaluation about the possible kind of ocean energy that can be harvested and the locations along the Colombian coast where these energies are available [38]. From this study, it can be concluded that at the Colombian Caribbean coast, the ocean energy to be exploited is mainly the salinity gradients. Near to the coast of San Andrés Island, thermal gradients can be a good option to generate electricity. Finally, regarding to the Colombian Pacific Coast, the energy of waves and tides can be used to produce electric power. In the current work, the parameters given in Table 3 were used to determine the behavior of the device designed. To carry out the simulations, Bahía Solano conditions were chosen; due to Chocó is a department that adjoints with the Pacific Ocean and a high percentage of its population is not connected to the national electric interconnection system. 


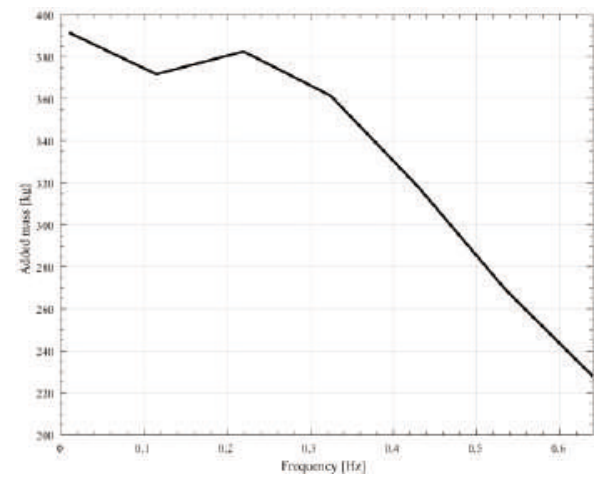

(a) Added mass
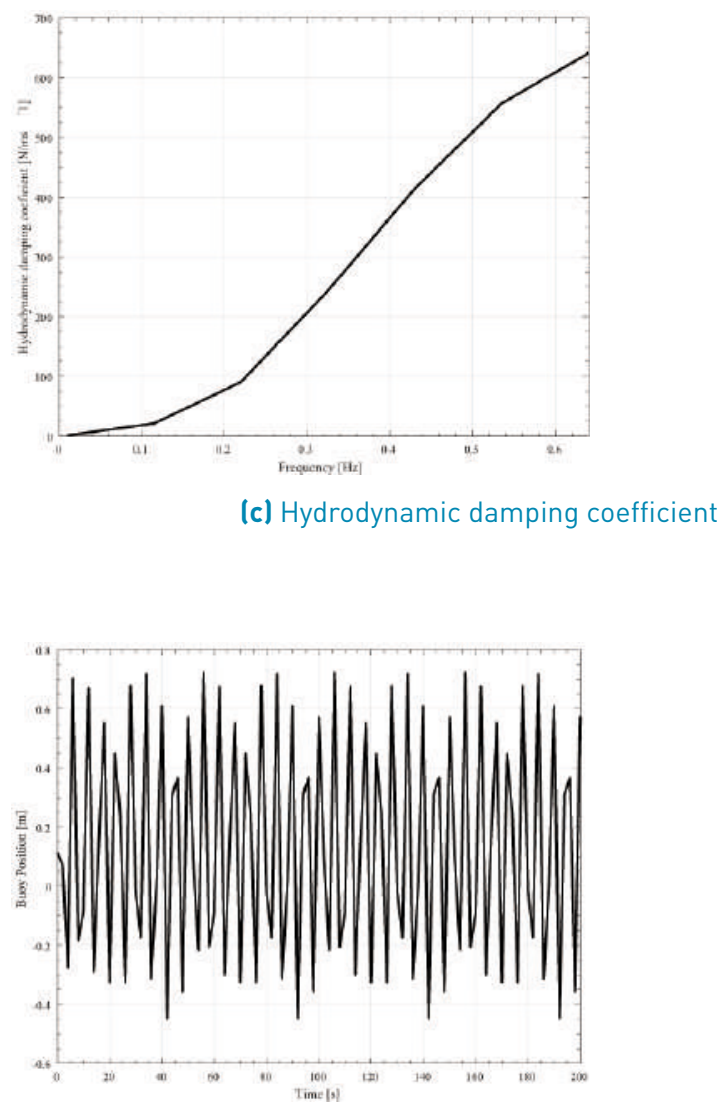

(a) Buoy position at z-axis

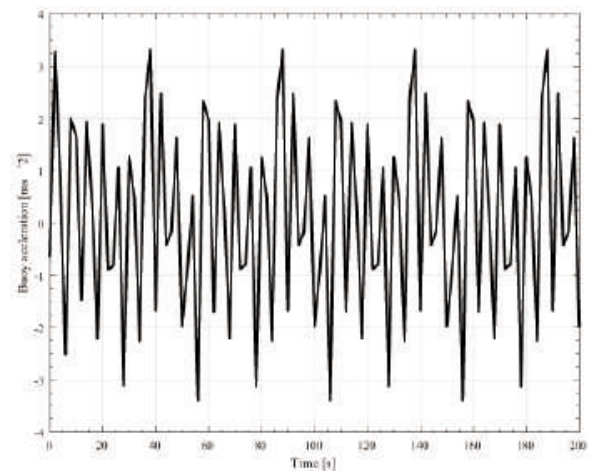

(c) Buoy acceleration in z-axis

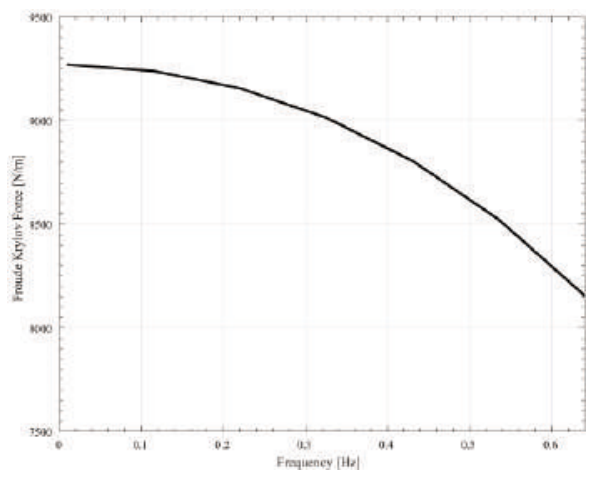

(b) Froude-Krylov force

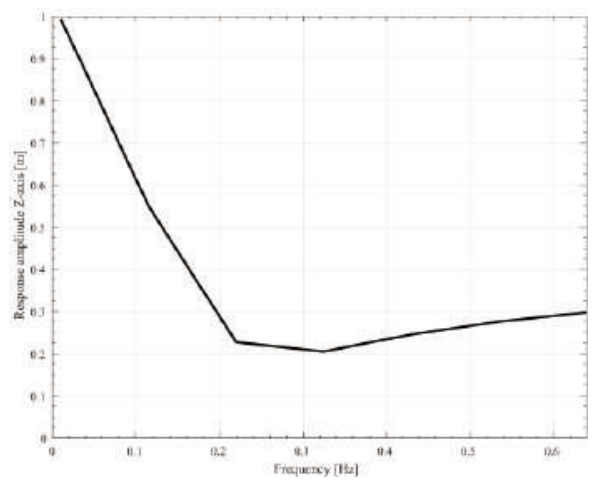

(d) Amplitude of oscillation across z-axis

Figure 6 Hydrodynamic diffraction analysis results

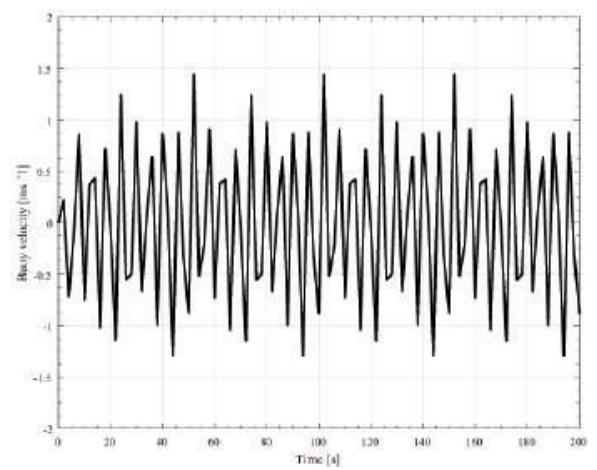

(b) Buoy velocity in z-axis

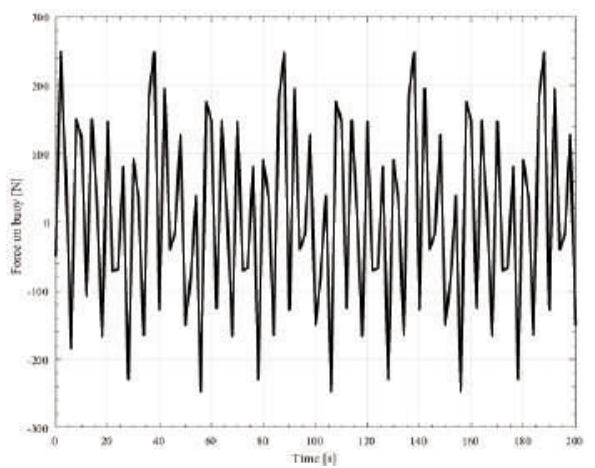

(d) Resulting force on buoy in z-axis

Figure $\mathbf{7}$ Hydrodynamic time response analysis results for an incident regular wave 


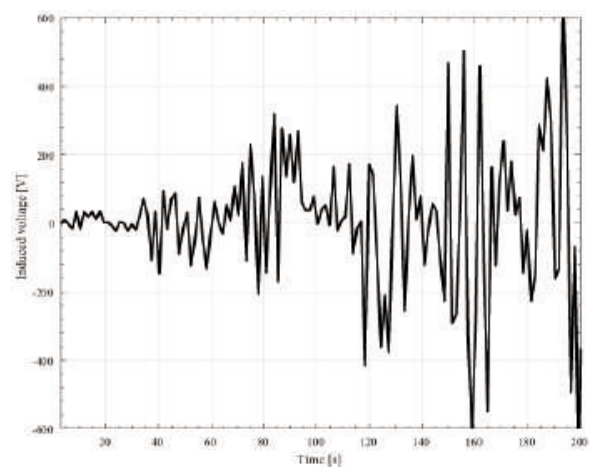

(a) Induced voltage

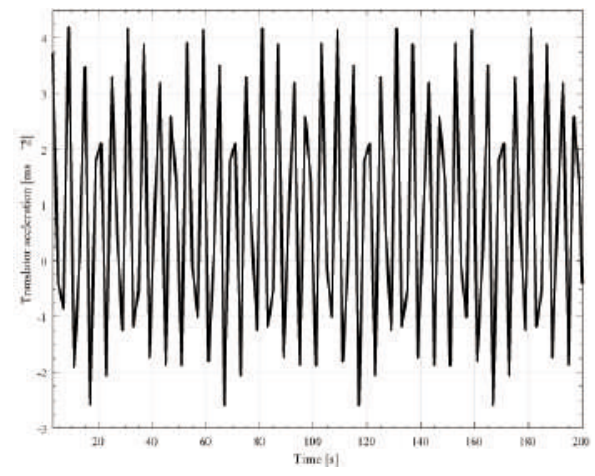

(c) Translator acceleration

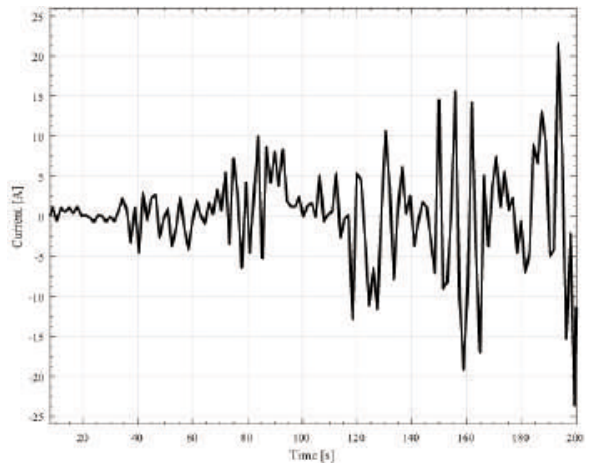

(b) Current at coils

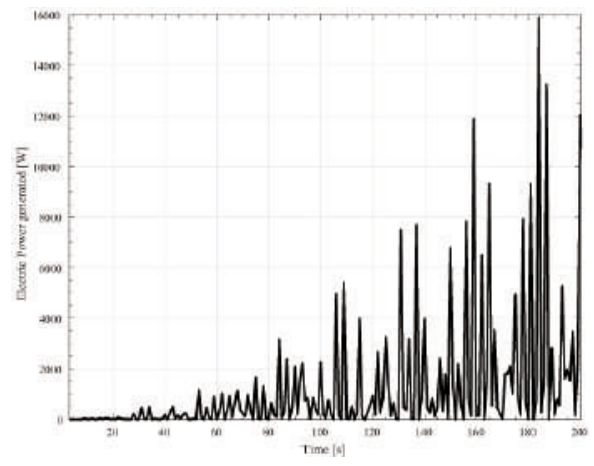

(d) Instant electric power

Figure 8 Electric power generated with incoming regular wave

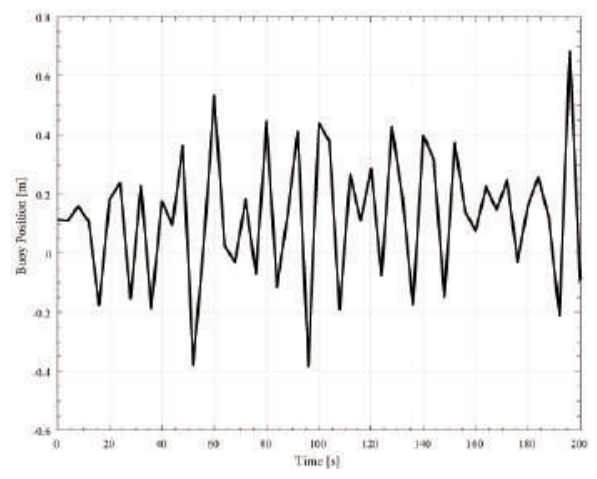

(a) Buoy position at z-axis

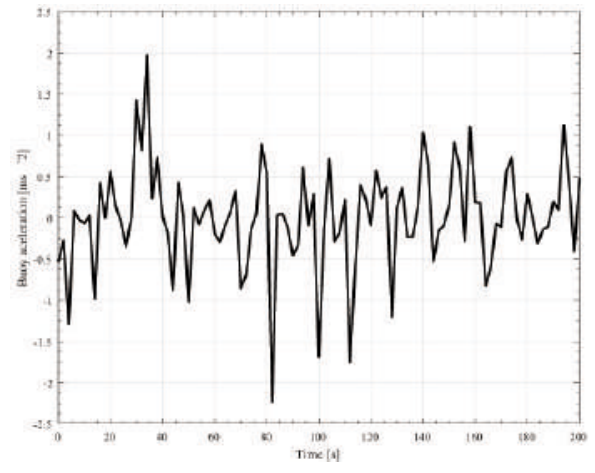

(c) Buoy acceleration in z-axis

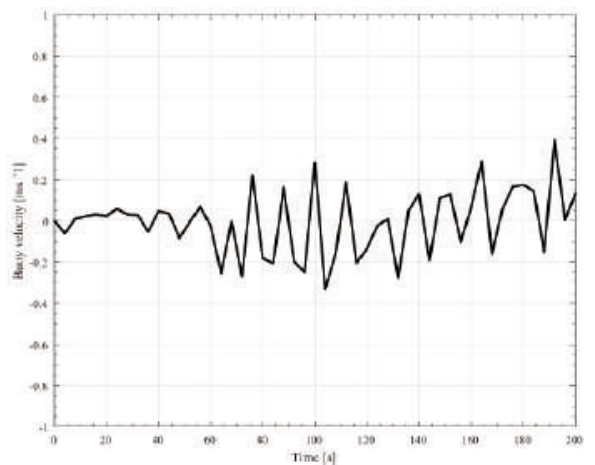

(b) Buoy velocity in z-axis

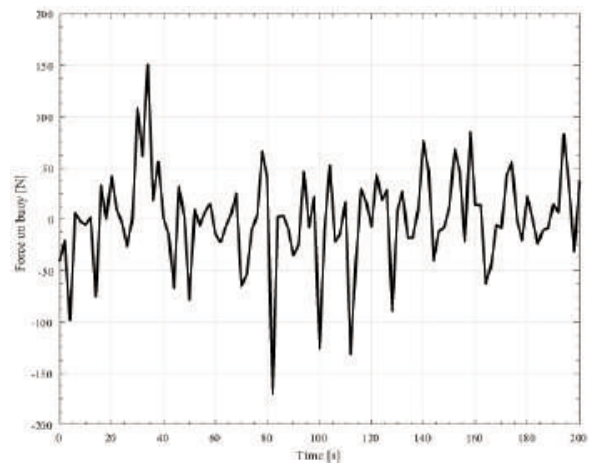

(d) Resulting force on buoy in z-axis

Figure 9 Hydrodynamic time response analysis results for an incident irregular wave 


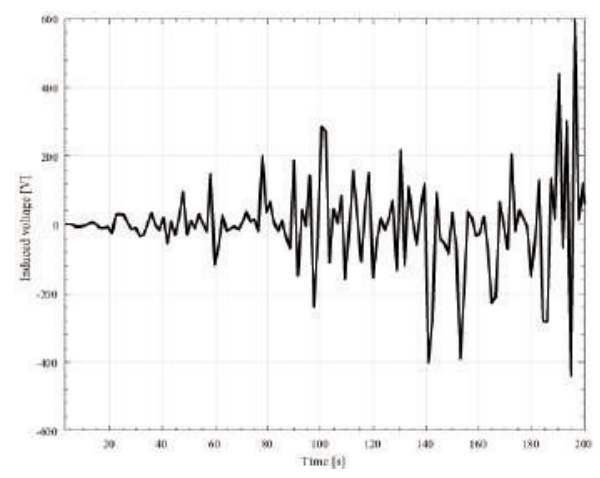

(a) Induced voltage

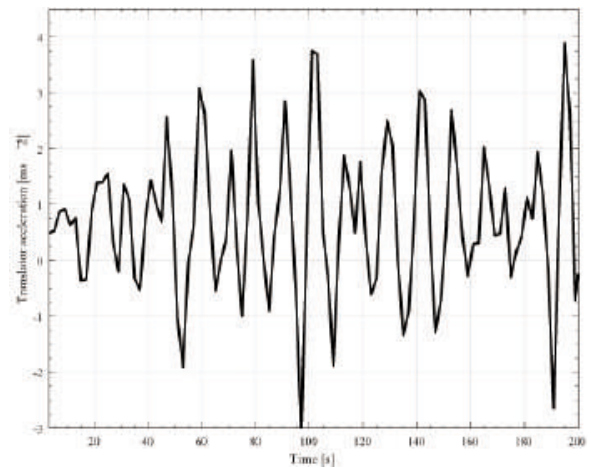

(c) Translator acceleration

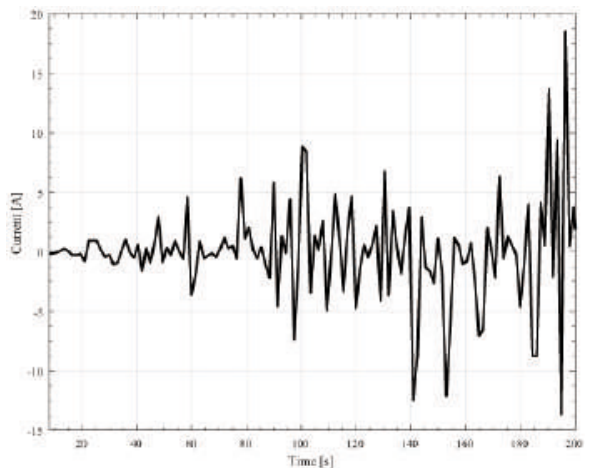

(b) Current at coils

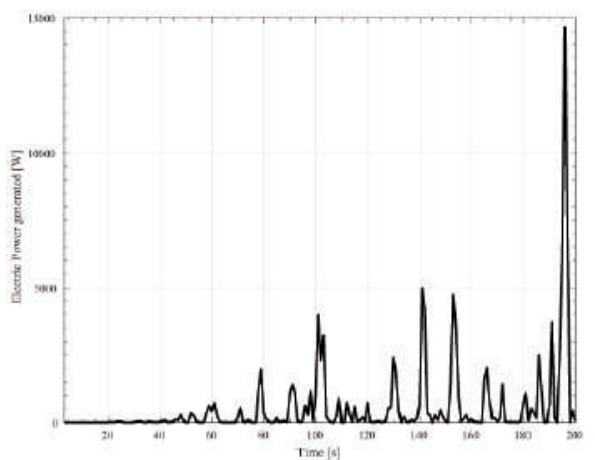

(d) Instant electric power

Figure 10 Electric power generated with incoming irregular wave

To know the behavior of the WEC in Ansys Aqwa ${ }^{\circledR}$, executing a Hydrodynamic Diffraction analysis is required first with the final purpose to determine the variation of the effects on the buoy with the frequency. To carry out this simulation, mass properties of the bodies should be configured at the center of gravity of each body. The connection between the support and the arm was configured as a kinematic pair of revolute, in order to the arm rotates around the connection point, as it was exposed in the operation of the system. Lastly, the arm was defined as a body free to move, and the support was fixed in a place. In this study, the frequency domain was setup to embrace the interval of frequencies proper of the Pacific Ocean. Likewise, the direction of the waves was configured to be $90^{\circ}$ perpendicular to the buoy. The computational procedure employed in this work can be outline as observed in the flow chart of Figure 5.

Figure 6 shows the results of this simulation. Figure ba) corresponds to the variation of the added mass with the frequencies. As observed, the value of the added mass decays with the increase of the frequency. The added mass physically represents an additional force that opposes the movement. A desired result is that the value of this mass is as small as possible. From Figure 6a), it can be concluded that higher values of frequency will lead to a better performance of the device.
In turn, Figure 6b) represents the variation of Froude-Krylov force with the frequency, being the force on the buoy major for small frequencies. Therefore, the minimum value is $8100 \mathrm{Nm}^{-1}$. It is important to note that this force is related with the wave amplitude; for this reason, it has $\mathrm{Nm}^{-1}$ units. Under lower frequencies, the Froude-Krylov force is higher, which in turn causes an increase in the vertical movement of the buoy and, subsequently, in the angle within the $X Y$ plane. This causes that the velocity of the translator is higher as well as the electric power generated. Figure $6 \mathrm{c}$ ) illustrates the behavior of the hydrodynamic damping coefficient; as it can be observed, this coefficient is higher under high values of frequency; then, working at lower frequencies is preferred. Finally, in Figure 6d) the buoy response amplitude across z-axis is presented; this figure supports the conclusion previously mentioned related to the device working under the effect of lower frequencies. For Joaquín and coworkers, the punctual absorbers work better when their natural frequency is in resonance with the wave frequencies, which suggest that the natural frequency of the device is around 0.1-0.2 $\mathrm{Hz}$ [39].

Fusco et al., found that the low frequency components of the wave spectra are the most interesting from an energetic point of view, as a very significant portion of the 
wave energy is usually concentrated at low frequencies. In addition, with respect to high frequency components, low frequency waves are more regular and less affected by nonlinearities, so that they can be predicted more accurately [40].

Previously, the results of the hydrodynamic diffraction analysis were presented; now, the results of the hydrodynamic time response are analyzed. In this simulation, a temporal domain of $200 \mathrm{~s}$ was used. Two simulations were carried out taking into account, as swell parameters, the significant wave height and the zero crossing period. These data are given in Table 3 for the case of the buoy in Bahia Solano. The first simulation allows knowing the behavior of the system under the effect of Airy wave theory. In this study, the response at a representative frequency of the interval is analyzed, being $0.32 \mathrm{~Hz}$ the mean value, in this case. For the second study, the effect of an irregular wave on the buoy was evaluated. For this purpose, an irregular wave spectrum was setup; here, the Pierson-Moskowitz spectrum was used since according to Joaquin and coworkers, it is the most adequate to sea conditions of swell produced by wind and completely developed [39]. This kind of swell corresponds to the conditions exhibited in the Colombian Pacific Ocean [37]. The Pierson-Moskowitz spectrum is formulated in terms of the two parameters of significant wave height equal to $1.17 \mathrm{~m}$ and average (Zero Crossing Period) wave period equal to $10.61 \mathrm{~s}$. $P$ in a regular wave, using the Airy wave theory, was equal to $2.504 \mathrm{~kW} / \mathrm{m}$; on the other hand, using Pierson-Moskowitz spectrum for the case of an irregular wave, the value of $P$ was equal to 7.97 $\mathrm{kW} / \mathrm{m}$. The results concerning the variation of velocity, acceleration, resultant force and elevation of the buoy are shown in Figure 7 and Figure 9, for regular and irregular waves, respectively.

Comparing the behavior of the buoy of both analyses, it is evident that under a regular wave the system has a better performance that when an irregular wave interacts with the device. This can be explained because, under the action of a regular wave, the parameters have high values if compared with the irregular wave results.

Regarding to the electric power generated, as indicated above, a Matlab ${ }^{\circledR}$ routine was developed to determine it. For this purpose, the elevation of the buoy data was exported to Matlab $®$ and the inclination angle value was calculated. To do this, the arm inclination angle was related to the buoy position through a trigonometric function. The value of acceleration (Equation 28) was used in Equation 29 and Equation 30, from which the translator velocity and position were calculated at each time step. Using Watt's law, the current was calculated utilizing the complex number form to determine, finally, the instantaneous electric power generated (Equation 31). In this paper, the losses in the generator due to various effects (Joule, parasitic currents, losses in the air gap, etc.) are negligible; hence, the electric power calculated is the total power produced. The result can be seen in Figure 8 and Figure 10, for a regular and an irregular wave, respectively.

As it can be seen, comparing the results of time response analysis, when the system works under the regular wave the results are more regular that in the case of an irregular wave. It can be noted that the fluctuation directly influences the electric power output of the device. In the power output shown in Figure 8d, the peak-to-average power ratio of the WEC system is higher than that in Figure 10d. However, according to Airy wave theory and Pierson-Moskowitz spectrum, it would be expected that the output power would be greater for an irregular wave because the spectrum considers all the wave train that travels inside the envelope wave. The difference in values $P$ is due to the fact that a higher frequency was used to model the regular wave than to model the irregular wave. According to Airy wave theory, as the wave frequency is increased, $P$ is greater $[9,25,41,42]$.

The velocity, acceleration and net force over the buoy reach higher peak values when a regular wave interacts with the buoy. Consequently, under a regular wave, the system presents more regularity in functioning. This is adequate for electric power generation because it is easier to configure the electronic control system used to make the energy exploitable.

It is important to mention that in the analysis of electric energy generation; the time of analysis excludes the first 3 s due to by default Ansys Aqwa ${ }^{\circledR}$ starts the analysis with a ramp signal, being the simulation in transitional state during this time. Because of this fact, the time of calculus is from 3 to $200 \mathrm{~s}$. As mentioned previously, the electric power generated overflows due to the losses and the effect of the magnetic field created by the induced field can be considered as negligible. To determine the average of the electric power obtained a code in Matlab ${ }^{\circ}$ was used. While for regular waves the device produces $1.17 \mathrm{~kW}$, under the effect of irregular waves the device only can produce $0.5 \mathrm{~kW}$. Assuming that the maximum power is generated under regular waves, the device under real conditions only has $42.7 \%$ of efficiency.

\section{Conclusion}

A WEC was designed for specific Colombian Pacific swell. First, the device behavior with respect to the frequency was analyzed. There was concluded that the system works better at lower frequencies. Due to the low components 
of a wave spectra are more energetic and regular that high frequency's one, under lower frequencies, $F_{E x c}$ is higher, which in turn results in an increase of the vertical movement of the buoy and, subsequently, the angle within the $X Y$ plane is larger. This causes that the velocity of the translator is higher as well as the electric power generated. Second, the time domain analysis was carried out. Under regular waves, the system shows a better and more regular behavior. Finally, the electric power generated was estimated without considering the losses in the generator. Under the effect of a regular wave the amount of energy was higher, contrary to what expected due to the fact that a greater frequency was used to model the regular wave. According to Airy wave theory, as the wave frequency is increased, $P$ is greater.

The device proposed here can be an alternative option to generate electric power from ocean waves. To supply the energy demand of small communities near to the Pacific coast, a wave energy farm constituted by several devices as the proposed here is required. It is interesting that the possibilities and shapes to harvest the wave energy have no limitations; only catching the wave movement and transforming it in a relative movement between permanent magnets and coils is needed. The WEC proposed exhibited a better performance under lower frequencies, within the range $0.05-0.15 \mathrm{~Hz}$.

The electric power generated is a function of the wave amplitude and the wave width captured. The amount of electric power produced might be greater if the proposed device dimensions are larger; nevertheless, transportation could be limited since the system has been designed for areas of difficult access.

\section{Acknowledgments}

The authors gratefully acknowledge the financial support from Universidad de Antioquia.

\section{References}

[1] M. A. Mustapa and et al., "Wave energy device and breakwater integration: A review," Renewable and Sustainable Energy Reviews, vol. 77, pp. 43-58, Sep. 2017.

[2] A. F. O. Falcão and J. C. C. Henriques, "Oscillating-water-column wave energy converters and air turbines: A review," Renewable Energy, vol. 85, pp. 1391-1424, Jan. 2016.

[3] J. Falnes, "A review of wave-energy extraction," Marine Structures, vol. 20, no. 4, pp. 185-201, Oct. 2007.

[4] B. Drew and A. R. P. M. N. Sahinkaya, "A review of wave energy converter technology," Proceedings of the Institution of Mechanical Engineers, Part A: Journal of Power and Energy, vol. 223, no. 8, pp. 887-902, 2019.

[5] A. F. de Falcão, "Wave energy utilization: A review of the technologies," Renewable and Sustainable Energy Reviews, vol. 14, no. 3, pp. 899-918, Apr. 2010.
[6] M. Penalba, G. Giorgi, and J. V. Ringwood, "Mathematical modelling of wave energy converters: A review of nonlinear approaches," Renewable and Sustainable Energy Reviews, vol. 78, pp. 1188-1207, Oct. 2017.

[7] T. K. A. Brekken, A. von Jouanne, and H. Y. Han, "Ocean wave energy overview and research at oregon state university," in 2009 IEEE Power Electronics and Machines in Wind Applications, June 2009, pp. 1-7.

[8] N. Khan, A. Kalair, N. Abas, and A. Haider, "Review of ocean tidal, wave and thermal energy technologies," Renewable and Sustainable Energy Reviews, vol. 72, pp. 590-604, May 2017.

[9] J. Goggins and W. Finnegan, "Shape optimisation of floating wave energy converters for a specified wave energy spectrum," Renewable Energy, vol. 71, pp. 208-220, Nov. 2014.

[10] B. J. Ruiz and V. Rodríguez, "Renewable energy sources in the colombian energy policy, analysis and perspectives," Energy Policy, vol. 34, no. 18, pp. 3684-3690, Dec. 2006.

[11] E. E. Gaona, C. L. Trujillo, and J. A. Guacaneme, "Rural microgrids and its potential application in colombia," Renewable and Sustainable Energy Reviews, vol. 51, pp. 125-137, Nov. 2015.

[12] T. Gómez and D. Ribo, "Assessing the obstacles to the participation of renewable energy sources in the electricity market of colombia," Renewable and Sustainable Energy Reviews, vol. 90, pp. 131-141, Jul. 2018.

[13] W. Vergara, A. Deeb, N. Toba, P. Cramton, and I. Leino, Wind Energy in Colombia A Frameworkfor Market Entry. Washington, D. C, USA: The World Bank, 2010.

[14] J. Arias, B. van der Zwaan, T. Kober, and S. Arango, "The prospects for small hydropower in colombia," Renewable Energy, vol. 107, pp. 204-214, Jul. 2017.

[15] P. E. Carvajal, F. G. N. Li, R. Soria, J. Cronin, G. Anandarajah, and Y. Mulugetta, "Large hydropower, decarbonisation and climate change uncertainty: Modelling power sector pathways for ecuador," Energy Strategy Reviews, vol. 23, pp. 86-99, Jan. 2019.

[16] J. G. Rueda and et al., "Renewables energies in colombia and the opportunity for the offshore wind technology," Journal of Cleaner Production, vol. 220, pp. 529-543, May 2019.

[17] D. Rodríguez and L. Rodríguez, "Photovoltaic energy in colombia: Current status, inventory, policies and future prospects," Renewable and Sustainable Energy Reviews, vol. 92, pp. 160-170, Sep. 2018.

[18] D. B. Asprilla, C. F. Valdés, R. J. Macías, and F. Chejne, "Evaluation of potential of energetic development in isolated zones with wide biodiversity: Niz chocó-colombia case study," Thermal Science and Engineering Progress, vol. 8, pp. 109-117, Dec. 2018.

[19] S. Zapata and et al., "Long-term effects of 100 on the colombian power market," Sustainable Energy Technologies and Assessments, vol. 30, pp. 183-191, Dec. 2018.

[20] R. D. M. Ramírez, F. I. Cuervo, and C. A. M. Rico, "Technical and financial valuation of hydrokinetic power in the discharge channels of large hydropower plants in colombia: A case study," Renewable Energy, vol. 99, pp. 136-147, Dec. 2016.

[21] Y. Olaya, S. Arango, and E. R. Larsen, "How capacity mechanisms drive technology choice in power generation: The case of colombia," Renewable and Sustainable Energy Reviews, vol. 56, pp. 563 - 571, Apr. 2016.

[22] A. F. Osorio, R. D. Montoya, J. C. Ortiz, and D. Peláez, “Construction of synthetic ocean wave series along the colombian caribbean coast: A wave climate analysis," Applied Ocean Research, vol. 56, pp. 119-131, Mar. 2016.

[23] A. Osorio and et al, "Building a roadmap for the implementation of marine renewable energy in colombia," Jun. 2011.

[24] E. Banguero, A. J. Aristizábal, and W. Murillo, "A verification study for grid-connected $20 \mathrm{kw}$ solar pv system operating in chocó, colombia," Energy Procedia, vol. 141, pp. 96 - 101, Dec. 2017, power and Energy Systems Engineering.

[25] J. Falnes, Ocean waves and oscillating systems: linear interactions including wave-energy extraction. Cambridge, United Kingdom: Cambridge University Press, 2002.

[26] G. Lavidas, "Energy and socio-economic benefits from the development of wave energy in greece," Renewable Energy, vol. 132, pp. 1290-1300, Mar. 2019. 
[27] A. Ilyas, S. A. R. Kashif, M. A. Saqib, and M. M. Asad, “Wave electrical energy systems: Implementation, challenges and environmental issues," Renewable and Sustainable Energy Reviews, vol. 40, pp. 260-268, Dec. 2014.

[28] I. López, J. Andreu, S. Ceballos, I. M. de Alegría, and I. Kortabarria, "Review of wave energy technologies and the necessary power-equipment," Renewable and Sustainable Energy Reviews, vol. 27, pp. 413-434, Nov. 2013.

[29] F. P. Johnston, E. R. Johnston, D. Mazurek, P. Cornwell, and B. Self, Vector Mechanics for Engineers: Statics and Dynamics, 12th ed. McGraw-Hill Education, 2019.

[30] M. López, F. Taveira, and P. Rosa, "Numerical modelling of the ceco wave energy converter," Renewable Energy, vol. 113, pp. 202-210, Dec. 2017.

[31] E. Ozkop and I. H. Altas, "Control, power and electrical components in wave energy conversion systems: A review of the technologies," Renewable and Sustainable Energy Reviews, vol. 67, pp. 106-115, Jan. 2017.

[32] A. Montoya, "Modelado y control de centrales undimotrices con accionamiento directo mediante generador lineal ante oleaje irregular," Ph.D. dissertation, Universidad de Sevilla., España, 2014.

[33] R. Hansen, "Design and control of the powertake-off system for a wave energy converter with multiple absorbers," Ph.D. dissertation, 2013.

[34] G. Giorgi and J. V. Ringwood, "Analytical representation of nonlinear froude-krylov forces for 3-dof point absorbing wave energy devices," Ocean Engineering, vol. 164, pp. 749-759, Sep. 2018.

[35] G. Enríquez, El Libro Práctico de los Generadores - Transformadores y Motores Eléctricos, 1st ed. Mexico: Limusa, 2004.

[36] H. Young, R. Freedman, F. Sears, and et al, Física Universitaria con fisica moderna, 12th ed. Addison Wesley, 2003.

[37] J. Portilla, A. L. Caicedo, R. Padilla, and L. Cavaleri, "Spectral wave conditions in the colombian pacific ocean," Ocean Modelling, vol. 92, pp. 149-168, Aug. 2015.

[38] A. F. Osorio, S. Ortega, and S. Arango, "Assessment of the marine power potential in colombia," Renewable and Sustainable Energy Reviews, vol. 53, pp. 966-977, Jan. 2016.

[39] J. Arbó and A. Canela, "Proyecto owc: Diseño y optimización de una planta de energí undimotriz," M.S. thesis, Universitat Politécnica de Catalunya Barcelona Tech, Cataluña, España, 2011.

[40] F. Fusco and J. Ringwood, "A study on short-term sea profile prediction for wave energy applications," in $8^{\text {th }}$ European Wave and Tidal Energy Conference, EWTEC, Uppsala, Sweden., 2009, pp. 7-10.

[41] Z. Zang, Q. Zhang, Y. Qi, and X. Fu, "Hydrodynamic responses and efficiency analyses of a heaving-buoy wave energy converter with pto damping in regular and irregular waves," Renewable Energy, vol. 116, pp. 527-542, Feb. 2018.

[42] W. N. Sheng, R. Alcorn, and A. Lewis, "Optimising power take-offs for maximizing wave energy conversions," in the $30^{\text {th }}$ International Workshop on Water Waves and Floating Bodies, Bristol, UK, 2015. 